Laporan Kasus

\title{
Tata Laksana Komprehensif Dermatitis Stasis pada Geriatri
}

\author{
Shannaz N. Yusharyahya, ${ }^{\star}$ Natalia R. Sutanto, Adhika A. Lestari, Rhida S. Amalia, Melody F. Andardewi \\ Departemen Dermatologi dan Venereologi, Fakultas Kedokteran Universitas Indonesia- \\ Rumah Sakit Umum Pusat Nasional dr. Cipto Mangunkusumo, Jakarta \\ *Penulis korespondensi: nadiayusharyahya@yahoo.com \\ Diterima 15 Maret 2021; Disetujui 20 Oktober 2021 \\ https://doi.org/10.23886/ejki.9.1.236
}

\begin{abstract}
Abstrak
Dermatitis stasis merupakan penyakit kulit inflamasi yang umum terjadi di ekstremitas bawah, ditandai dengan eritema, skuama, erosi, krusta, dan terkadang juga dapat ditemukan vesikel, serta ulserasi kecil di kulit yang dikenal sebagai ulkus stasis atau ulkus venosum. Faktor risiko dermatitis statis antara lain usia di atas 50 tahun, obesitas, dan jenis kelamin perempuan. Dilaporkan tiga kasus dermatitis stasis pada pasien geriatri laki-laki yang datang ke Rumah Sakit dr.Cipto Mangunkusumo dan ketiganya disertai komorbiditas obesitas. Tata laksana pada ketiga pasien ini melibatkan departemen lain (multidisiplin) dan membuahkan hasil yang baik.
\end{abstract}

Kata kunci: dermatitis stasis, geriatri, tata laksana multidisiplin.

\section{Comprehensive Management of Stasis Dermatitis in the Elderly}

\begin{abstract}
Stasis dermatitis is an inflammatory skin disease that commonly occurs in the lower extremities, manifested with erythema, scale, erosion, crusting, and sometimes vesicles, small ulcers which are known as stasis ulcers or venous ulcers, can be found. The risk factors for stasis dermatitis include patients who are 50 years or older, obesity, and female. Three cases of stasis dermatitis were reported in male geriatric patients who were treated at geriatric dermatology clinic at Cipto Mangunkusumo Hospital. All of them have obesity as one of their comorbid. The management of these patients was done in collaboration with other departments (multidisciplinary) resulting a good outcome.

Keywords: stasis dermatitis, geriatrics, multidisciplinary management.
\end{abstract}




\section{Pendahuluan}

Kulit orang usia lanjut (lansia) atau geriatri mengalami penuaan intrinsik dan ekstrinsik yang dapat menimbulkan berbagai masalah kesehatan kulit antara lain insufisiensi vena kronik yang dapat bermanifestasi ke kulit sebagai dermatitis stasis. ${ }^{1}$ Dermatitis stasis adalah penyakit kulit inflamasi yang sering terjadi di ekstremitas bawah, biasanya merupakan gejala awal insufisiensi vena kronik dengan hipertensi vena dan prekursor kondisi kulit lain misalnya ulkus kronik dan lipodermatosklerosis. Insufisiensi vena kronik terjadi karena gangguan katup di pembuluh darah tungkai yang membantu mendorong darah kembali ke jantung. Kelemahan katup tersebut menyebabkan air dan sel darah berkumpul di tungkai bawah serta menimbulkan gejala seperti edema, inflamasi, nyeri, hingga ulkus venosum. ${ }^{1,2}$ Insidens insufisiensi vena kronik pada populasi dewasa di dunia yaitu 20$60 \%{ }^{3}$ Dermatitis stasis lebih sering terjadi pada orang berusia di atas 50 tahun dan jenis kelamin perempuan. Faktor risiko lainnya adalah genetik, varises, hipertensi, obesitas, riwayat operasi vena, hamil, gagal jantung kongestif, gagal ginjal, postur tubuh tinggi, aktivitas fisik minimal, dan memiliki pekerjaan/kebiasaan berdiri lama. ${ }^{1,4}$

Dermatitis statis ditandai dengan eritema, skuama, erosi, dan krusta. Terkadang dijumpai vesikel dan ulserasi kecil sebagai ulkus venosum. Gambaran klinis tersebut dapat terjadi di setiap tahap insufisiensi vena kronik. Seiring berjalanannya proses penyakit dapat ditemukan sklerosis panikulitis, hipodermatitis sklerodermiformis, atrophie blanche, lemak subkutan diganti oleh fibrosis, kulit kencang dan mengeras yang disebut lipodermatosklerosis, dan inverted champagne bottle appearance. Fibrosis menekan dan menghalangi aliran limfe sehingga menyebabkan edema di atas dan di bawah fibrosis. ${ }^{1,4}$

Dermatitis statis dapat dikontrol, tetapi tidak dapat disembuhkan karena kerusakan atau gangguan katup vena bersifat ireversibel. Meskipun tidak dapat disembuhkan, tata laksana yang tepat dapat membantu mengendalikan penyakit dan mencegah komplikasi. Tujuan tata laksana adalah menurunkan tekanan vena dan meningkatkan aliran vena serta limfe dengan cara mekanik, obat, dan pembedahan. Tata laksana mekanik adalah penggunaan stocking kompresi dan elevasi tungkai. Obat yang dapat diberikan adalah aspirin, pentoksifilin, dan kortikosteroid topikal. Antibiotik topikal atau oral diberikan jika terdapat tanda-tanda infeksi atau selulitis. ${ }^{1}$

Tata laksana dermatitis stasis pada pasien geriatri lebih kompleks dari populasi usia lainnya. Diperlukan pendekatan yang berbeda di tiap individu karena perlu mempertimbangkan komorbiditas lain yang diderita oleh pasien, serta perlunya keterlibatan dari departemen lain (multidisiplin) agar tata laksana yang dipilih dapat memberikan hasil yang terbaik untuk pasien. Dilaporkan tiga kasus dermatitis pada pasien geriatri yang berobat ke poliklinik Dermatologi Geriatri Rumah Sakit dr. Cipto Mangunkusumo (RSCM) tahun 2020 yang pada ketiganya dijumpai insufisiensi vena kronik dan obesitas.

\section{Kasus I}

Laki-laki, 61 tahun, mengeluh terdapat bercak kehitaman yang terasa gatal dan semakin menebal di kedua tungkai bawah sejak sebulan lalu. Jika duduk terlalu lama, berdiri lama atau banyak berjalan, kaki pasien membengkak. Bercak di kedua tungkai dialami sejak 10 tahun lalu, awalnya bercak berwarna kemerahan disertai lenting dan luka kecil. Pasien berobat ke poliklinik Dermatologi dan Venereologi (DV) RSCM sejak 10 tahun lalu, namun tidak kontrol rutin. Saat berobat, lesi membaik namun sering kambuh dan lama kelamaan kulit di kedua tungkai bawah menghitam, kering dan bersisik.

Pasien tidak bekerja, namun dahulu memiliki toko sehingga sering berdiri lama. Saat ini pasien lebih sering duduk atau berbaring tanpa mengangkat kaki seperti yang dianjurkan dokter, karena nyeri di punggung akibat hernia nukleus pulposus (HNP). Pasien memiliki obesitas, hipertensi, HNP lumbal dan insufisiensi vena kronik. Saat ini rutin mengonsumsi alpentin $1 \mathrm{x}$ $200 \mathrm{mg}$ dan ibuprofen $3 \times 500 \mathrm{mg}$, amlodipin $1 \times$ $10 \mathrm{mg}$, kandesartan $1 \times 8 \mathrm{mg}$, mekobalamin $2 \times$ $500 \mathrm{mcg}$, dan vitamin B kompleks 1 x 1 tablet.

Pada pemeriksaan fisik didapatkan tekanan darah 140/72 mmHg, indeks massa tubuh (IMT) $46,84 \mathrm{~kg} / \mathrm{m}^{2}$,tanda vital lain dan status generalis dalam batas normal. Status dermatologikus didapatkan makula-plak eritematosahiperpigmentasi multipel, plakat, ireguler, sirkumskrip, konfluens, skuama putih kering kasar di atasnya, serta atrophie blanche dan lipodermatosklerosis di 2/3 distal tungkai bawah bilateral (Gambar 1). 

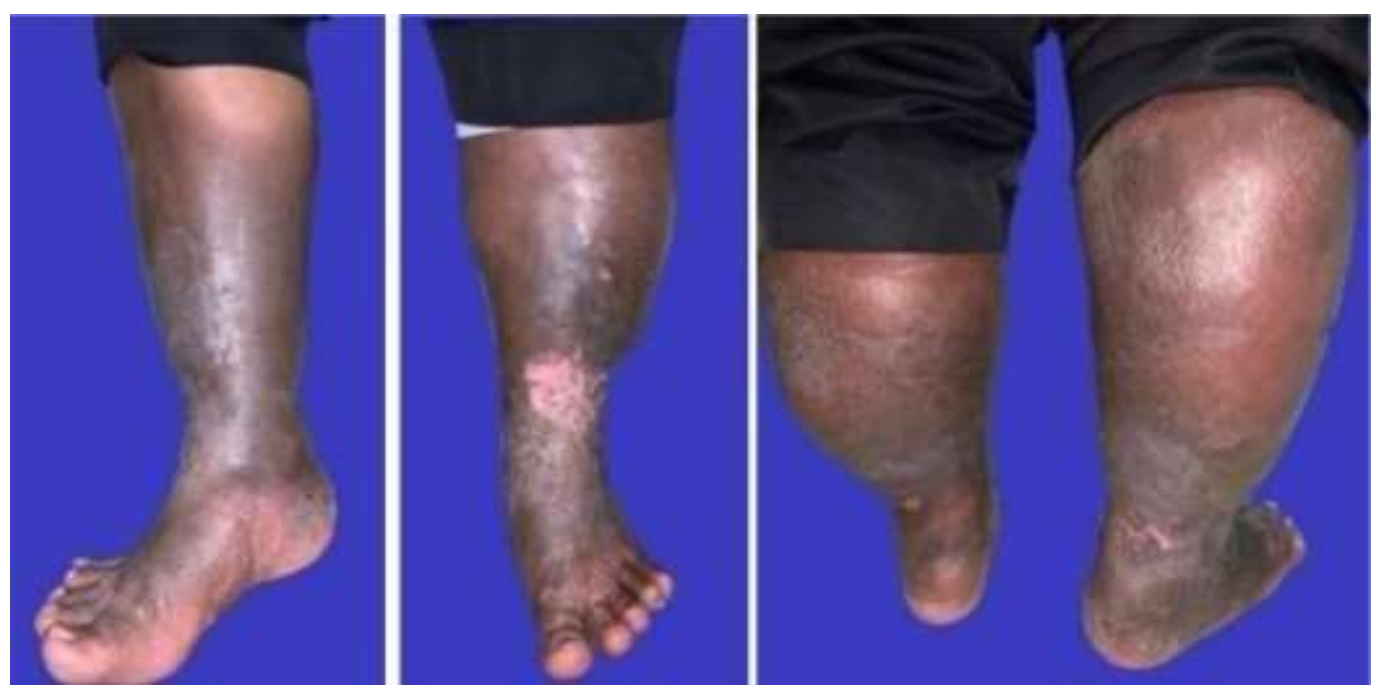

Gambar 1. Dermatitis Stasis pada Laki-Laki Usia 61 Tahun. Tampak lesi kulit makula hingga plak eritematosa, hiperpigmentasi dan lipodermatosklerosis di $2 / 3$ distal tungkai bawah.

Pemeriksaan ultrasonografi (USG) doppler oleh bedah vaskular menunjukkan sapheno-femoral junction dekstra dan sinistra dengan refluks positif dan trombus negatif. Didapatkan kesan gangguan katup bilateral yang menandakan insufisiensi vena kronik bilateral klasifikasi C4bEpAsPr. Pasien didiagnosis dermatitis stasis, insufisiensi vena kronik bilateral dan obesitas grade III.

Terapi yang diberikan adalah salep desoksimetason 2 kali sehari dan vaselin album setelah mandi, sedangkan dari bedah vaskular Ardium $2 \times 500 \mathrm{mg}$, Simarc $1 \times 2 \mathrm{mg}$, serta kompresi eksternal (stocking). Dari gizi klinik dianjuran diet rendah kalori 1700 kkal dalam bentuk makanan biasa. Latihan olahraga ringan diajarkan oleh departemen rehabitasi medik. Setelah 2 minggu tampak perbaikan dan pasien dianjurkan kontrol tiap bulan.

\section{Kasus II}

Laki-laki, 75 tahun, mengeluh bengkak di kedua tungkai disertai luka yang nyeri di kaki kanan sejak 2 minggu yang lalu. Di bagian tungkai yang bengkak terkadang membasah dan timbul luka lecet di beberapa tempat, hilang timbul sejak 3 tahun yang lalu. Tidak ada riwayat demam. Pasien memiliki riwayat hipertensi, insufisiensi vena kronik, osteoartritis lutut bilateral, dislipidemia, hiperurisemia asimtomatik, dan benign prostatic hyperplasia. Pasien pensiunan karyawan swasta, berolah raga 3 kali seminggu dengan jalan kaki atau sepeda statis selama 20 menit.

Pada pemeriksaan fisik, tanda vital dan keadaan umum dalam batas normal kecuali IMT $31,5 \mathrm{~kg} / \mathrm{m}^{2}$. Status dermatologikus di 1/2 distal tungkai bawah bilateral terdapat edema-eritema difus, tidak hangat pada perabaan, plak eritematosa-hiperpigmentasi, sebagian dengan erosi dan ekskoriasi, krusta kekuningan, dan inverted champagne bottle appearance. Di regio dorsum pedis dekstra terdapat ulkus soliter berukuran $3 \times 2 \times 0,5 \mathrm{~cm}$, bentuk ireguler, dasar jaringan granulasi, sebagian tertutup slough kekuningan, tepi tidak meninggi, dinding tidak bergaung, dan kulit sekitar hiperpigmentasi (Gambar 2).

Pasien didiagnosis dermatitis stasis dan ulkus venosum dengan infeksi sekunder, obesitas grade II dan insufisiensi vena kronik. Terapi yang diberikan adalah amoksisilin - asam klavulanat $3 \times 625 \mathrm{mg}$ per oral selama 7 hari dan salep asam fusidat $2 \%$ dua kali sehari setelah kompres kompres $\mathrm{NaCl}$ $0,9 \%$ di ulkus kaki kanan. Kedua tungkai dioles salep desoksimetason 2 kali sehari dan vaselin album. Dari bedah vaskular diberikan Ardium $1 \mathrm{x}$ $1000 \mathrm{mg}$ dan pemakaian stocking; dari gizi klinik diberikan diet rendah kalori. Saat kontrol 1 minggu, tanda-tanda infeksi tidak ada sehingga antibiotik dihentikan. Vaselin dan pemakaian stocking dilanjutkan seumur hidup dan pasien dianjurkan kontrol tiap bulan. 

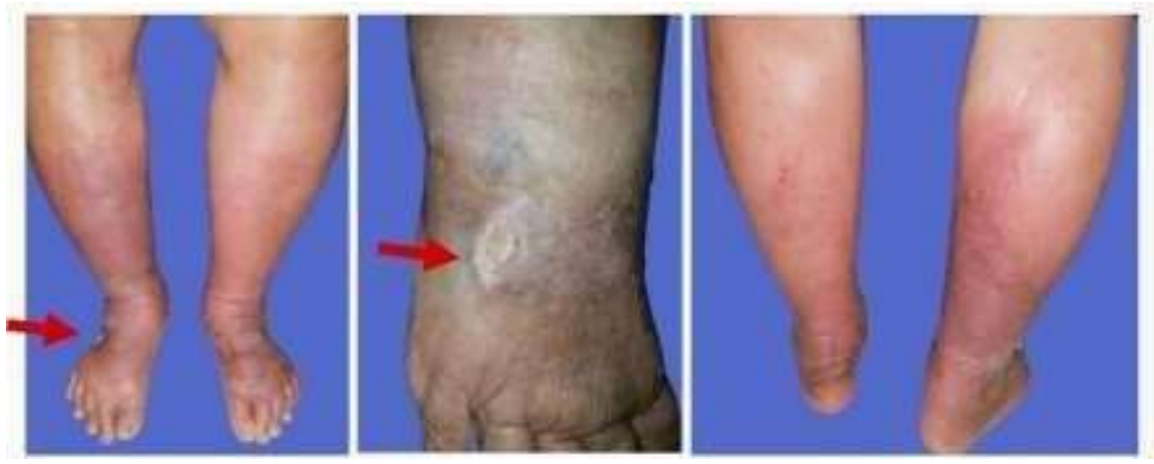

Gambar 2. Dermatitis Stasis pada Laki-Laki Usia 75 Tahun dengan Plak Eritematosa terutama 2/3 Distal Tungkai Bawah. Tampak ulkus venosum di dorsum pedis dekstra (panah merah).

\section{Kasus III}

Laki-laki, 74 tahun, mengeluh kulit bertambah kering dan menghitam di kedua tungkai bawah yang terasa memberat sejak 2 hari yang lalu. Tiga bulan yang lalu pasien mengeluh bengkak di kedua tungkai bawah disertai bercak kehitaman dan gatal namun tidak nyeri, demam, dan sekelan. Keluhan kulit kaki kering terutama di punggung kaki, pergelangan, dan tumit kanan. Tidak ada riwayat trauma, maupun kontak dengan bahan iritan atau bahan kimia di kaki. Pasien tidak mencuci kaki dengan sabun sejak 1 tahun yang lalu karena takut iritasi. Satu bulan yang lalu pasien berobat ke SpKK dan diberikan salep klobetasol, namun tidak ada perbaikan sehingga pasien dirujuk ke poliklinik DV RSCM untuk tata laksana lebih lanjut.

Pada pemeriksaan fisik, IMT $33,2 \mathrm{~kg} / \mathrm{m}^{2}$, tanda vital dalam batas normal. Status dermatologikus regio tungkai bawah bilateral $1 / 3$ distal terdapat plak tipis hiperpigmentasi multipel, lentikular hingga plakat, diskret hingga konfluens, sirkumskrip, dengan skuama putih kasar di atasnya dan varises multipel di beberapa tempat. Di regio dorsum pedis, tibia distal dekstra, maleolus medialis dekstra terdapat plak hiperpigmentasi, plakat, ireguler, sirkumskrip, diskret hingga konfluens, sebagian dengan likenifikasi. Hasil pemeriksaan USG doppler tungkai bawah oleh bedah vaskular didapatkan sapheno-femoral junction dekstra dan sinistra refluks positif, trombus negatif. Diperoleh kesan insufisiensi vena kronik tungkai bilateral klasifikasi C1EpAsPr.

Pasien didiagnosis dermatitis stasis, liken simpleks kronikus, insufisiensi vena kronik, dan obesitas grade II. Pasien diberikan salep klobetasol propionat, vaselin album sebagai pelembap dan stocking kompresi untuk dipakai setiap hari. Saat kontrol 2 minggu terdapat perbaikan, maka terapi dilanjutkan dan dianjurkan kontrol setiap bulan.
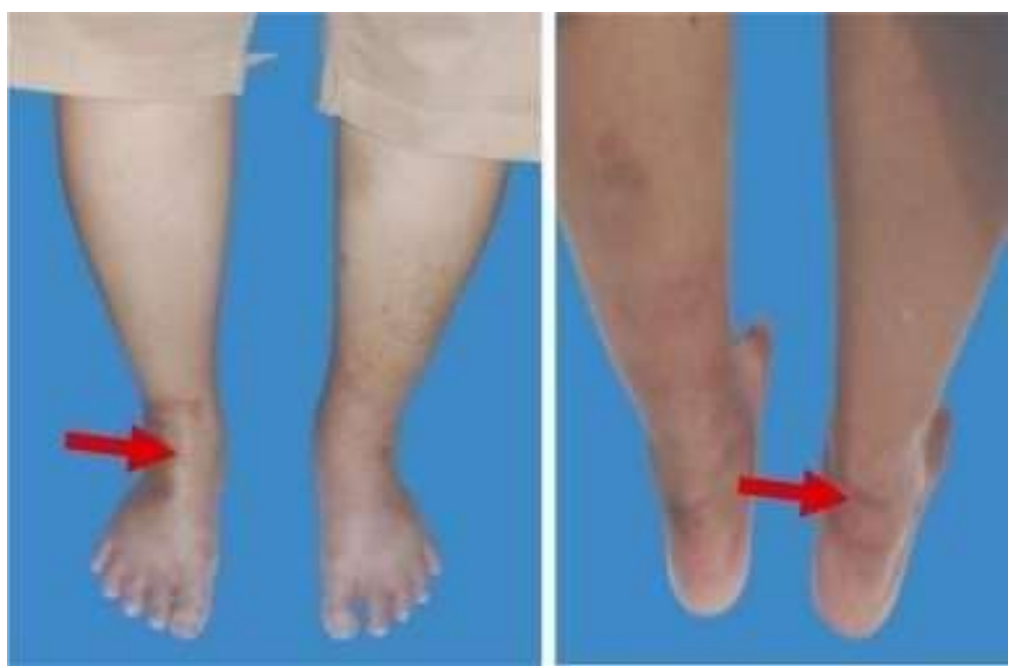

Gambar 3. Dermatitis Stasis pada Laki-Laki Usia 74 Tahun dengan Gambaran Lesi Plak Hiperpigmentasi dan Likenifikasi 


\section{Diskusi}

Kelompok geriatri memiliki faktor risiko untuk mengalami dermatitis stasis. ${ }^{1,4}$ Perubahan kulit pada dermatitis stasis adalah akibat perfusi oksigen yang buruk ke jaringan kulit ekstremitas bawah. Penyebab dermatitis stasis adalah venous pooling, arteriovenous shunting, peningkatan tekanan hidrostatik vena yang memengaruhi mikrosirkulasi, barier fibrin yang mencegah difusi oksigen, dan leukocyte trapping yang mengakibatkan kerusakan mikrovaskular. Dermatitis stasis dapat dijumpai di setiap tahap insufisiensi vena kronik dan merupakan prekursor untuk kondisi kulit lain misalnya, ulkus kronik dan lipodermatosklerosis. Kelainan kulit biasanya di supramalleolar medial karena mikroangiopati paling berat di daerah tersebut. ${ }^{5}$ Pada ketiga pasien ini lokasi dermatitis stasis di daerah tungkai bawah.

Insufisiensi vena kronik memberikan spektrum klinis bervariasi, mulai dari edema tungkai, nyeri tekan, hingga ulkus venosum yang sulit sembuh jika terdapat komorbiditas. Penyakit berlangsung kronik, lemak subkutan secara bertahap diganti fibrosis dari sekitar pergelangan kaki menjalar ke arah proksimal yang disebut lipodermatosklerosis dan terdapat atrophie blanche, seperti yang dialami oleh pasien kasus I dan II. Fibrosis semakin menekan dan menghalangi aliran limfe yang menyebabkan edema di atas dan di bawah fibrosis sehingga jika pasien berjalan lama atau duduk lama, kaki menjadi bengkak..$^{1,6}$ Faktor risiko ulkus venosum pada insufisiensi vena kronis berupa usia tua, IMT tinggi $\left(>25 \mathrm{~kg} / \mathrm{m}^{2}\right)$, refluks vena dalam, terdapat pada ketiga pasien ditambah dengan kurangnya aktivitas fisik pada pasien kasus I.

Diagnosis dermatitis stasis terutama ditegakkan dari anamnesis dan pemeriksaan fisik seperti pada ketiga kasus diatas. Pemeriksaan USG doppler perlu dilakukan untuk mengetahui inkompetensi katup vena di kedua tungkai untuk menegakkan diagnosis insufisiensi vena kronik. ${ }^{1,8}$ Klasifikasi insufisiensi vena kronik pada kasus pertama C4bEpAsPr dan kasus III C1EpAsPr. Klasifikasi Clinical-Etiology-AnatomyPathophysiology (CEAP) adalah klasifikasi standar untuk menggambarkan pasien dengan gangguan vena kronik. C memberikan gambaran klinis berdasarkan tanda-tanda obyektif, E berarti etiologi, A menggambarkan distribusi refluks anatomis, sedangkan $\mathrm{P}$ menggambarkan patofisiologi obstruksi di vena yang mendasarinya, baik karena refluks atau obstruksi. C4b diartikan sebagai gambaran klinis lipodermatosklerosis atau athropie blanche, Ep adalah etiologi primer, As berarti terdapat gangguan di vena superfisial, sedangkan Pr berarti gambaran refluks di katup vena. ${ }^{9}$

Keberhasilan terapi dermatitis stasis bergantung pada pengobatan insufisiensi vena sehingga pasien diberikan stocking, dipakai sepanjang hari untuk membantu mengurangi tekanan di pembuluh darah. Kelainan di vena bersifat ireversibel sehingga terapi kompresi sebaiknya seumur hidup. ${ }^{6,10}$ Ketiga pasien, disarankan menggunakan stocking oleh bedah vaskular, untuk memperbaiki tekanan di kedua tungkai sehingga aliran darah vena lebih lancar, edema tungkai berkurang, dan lesi kulit membaik.

Tata laksana lain pada ketiga pasien diatas adalah pemberian edukasi mengenai penyakit, pencegahan perburukan, dan mencegah friksi atau trauma yang dapat mencetuskan lesi atau ulkus venosum yang merupakan komplikasi tersering insufisiensi vena kronik. Edukasi yang diberikan adalah menghindari pakaian dan alas kaki yang ketat dan kasar, mencegah menggaruk kulit jika gatal, menggunakan pelembap secara rutin, menggunakan stocking secara rutin, elevasi tungkai agar posisi tungkai lebih tinggi daripada jantung sehingga mempermudah aliran balik vena, serta menghindari posisi berdiri atau duduk dalam waktu lama secara terus-menerus. ${ }^{6,11}$

Ketiga pasien memiliki obesitas (IMT> 25 $\mathrm{kg} / \mathrm{m}^{2}$ ) yang merupakah salah satu faktor risiko dan komorbid insufisiensi vena., ${ }^{1,4}$ Obesitas meningkatkan tekanan abdomen dan sekresi adipokin yang mengakibatkan disfungsi mikrosirkulasi vena tungkai. ${ }^{12}$ Obesitas juga memperberat kondisi HNP pasien kasus I. Oleh sebab itu, tata laksana harus meliputi penurunan berat badan dengan modifikasi gaya hidup yaitu mengatur asupan nutrisi, aktivitas fisik teratur, dan modalitas lainnya. ${ }^{13}$ Ketiga pasien sudah dikonsulkan ke poliklinik Gizi dan disarankan untuk mengubah pola makan menjadi diet rendah kalori untuk mengurangi berat badan sehingga membantu memperbaiki aliran darah vena di tungkai dan diet rendah garam untuk membantu mengurangi edema tungkai. Kasus I juga dikonsulkan ke poliklinik Rehabilitasi Medik RSCM agar dapat melakukan gerakan olahraga tanpa memperberat HNP.

Untuk tata laksana insufisiensi vena lainnya, kasus I diberikan Simarc 2 mg sehari, kasus I dan II diberikan ardium 500 mg dua kali sehari dari poliklinik bedah vaskular. Simarc adalah nama dagang antikoagulan warfarin sodium. Tujuan pemberian antikoagulan adalah mencegah komplikasi tromboemboli vena akibat regurgitasi di katupvena. 
Pasien lansia lebih mudah mengalami tromboemboli vena dibandingkan pasien lebih muda dan memiliki angka morbiditas dan mortalitas lebih tinggi terkait tromboemboli vena, terutama pasien dengan komorbiditas gangguan katup vena dan imobilisasi. ${ }^{14}$ Ardium mengandung micronized purified flavonoid fraction (MPFF) golongan phlebotropic semisintesis yang dapat meningkatkan drainase limfe, mendukung mikrosirkulasi, meningkatkan tonus dan elastisitas vena. ${ }^{15}$ MPFF secara signifikan memperbaiki gejala insufisiensi vena tungkai yaitu nyeri, kaki terasa berat, bengkak, kram, parestesia, sensasi terbakar, dan pruritus dan dapat mengurangi inflamasi di tungkai, perubahan. ${ }^{16}$

Pada dermatitis stasis, pemberian steroid topikal dan pelembap membantu resolusi lesi kulit. ${ }^{1,17,18}$ Ketiga pasien mendapat steroid topikal dan vaselin album sebagai pelembap. Saat kontrol 2 minggu, ketiganya merasa keluhan kulit mengalami perbaikan. Plak mulai menipis, kulit tidak terasa kering, dan gatal berkurang. Pada geriatri, dermatitis stasis memerlukan tata laksana komprehensif dan melibatkan kerja sama dokter spesialis DV, spesialis bedah vaskular, spesialis gizi klinik, serta spesialis rehabilitasi medik bila diperlukan.

Prognosis pada ketiga kasus ini adalah dubia ad malam karena insufisiensi vena merupakan penyakit kronik yang dapat dikontrol, tetapi tidak dapat disembuhkan. Selain itu, lesi kulit cukup luas dan kaki menjadi bengkak jika berjalan atau berdiri lama dapat memengaruhi aktivitas pasien seharihari dan menurunkan kualitas hidupnya.

\section{Kesimpulan}

Dermatitis stasis memerlukan tata laksana secara komprehensif. Keberhasilan terapi dipengaruhi oleh perbaikan kondisi insufisiensi vena, perawatan kulit dengan terapi topikal, mengatasi kondisi penyerta yang dapat memperberat gejala, serta modifikasi gaya hidup.

\section{Daftar Pustaka}

1. Newman SA. Cutaneous changes in arterial, venous, and lymphatic dysfunction. In: Kang S AM, Brucker AL, Enk AH, Margolis DJ, McMichael AJ, et al, editors. Fitzpatrick's dermatology. Edisi ke-9. New York: McGraw Hill Education;2019.p.2670-99.

2. Marks JG, Miller JJ. Lookingbill and Marks' principles of dermatology. Edisi ke-6. New York: Elsevier; 2019.p.95-112.

3. Feodor T, Baila S, Mitea IA, Branisteanu DE, Vittos O. Epidemiology and clinical characteristics of chronic venous disease in Romania. Exp Ther Med. 2019;17:1097-105. doi: 10.3892/etm.2018.7059.
4. Youn YJ, Lee J. Chronic venous insufficiency and varicose veins of the lower extremities. Korean J Intern Med. 2019;34:269-83. doi: 10.3904/ kjim.2018.230.

5. Montminy ML, Jayaraj A, Raju S. A systematic review of the efficacy and limitations of venous intervention in stasis ulceration. J Vasc Surg Venous Lymphat Disord. 2018;6:376-98. doi: 10.1016/j. jvsv.2017.11.007

6. Sung CT, Taguines PR, Jacob SE. Stasis dermatitis. J Dermatol Nurses Assoc. 2019;11:134-36. doi: 10.1097/JDN.0000000000000463

7. Meulendijks AM, de Vries FMC, van Dooren AA, Schuurmans MJ, Neumann HAM. A systematic review on risk factors in developing a first-time venous leg ulcer. J Eur Acad Dermatol Venereol. 2019;33: 1241-8. doi: 10.1111/jdv.15343.

8. Bergkvist M, Henricson J, Iredahl F, Tesselaar E, Sjoberg F, Farnebo S. Assessment of microcirculation of the skin using tissue viability imaging: a promising technique for detecting venous stasis in the skin. Microvasc Res. 2015;101:20-5. doi: 10.1016/j. mvr.2015.06.002.

9. Lurie F, Passman M, Meisner M, Dalsing M, Masuda $\mathrm{E}$, Welch $\mathrm{H}$, et al. The 2020 update of the CEAP classification system and reporting standards. J Vasc Surg Venous Lymphat Disord. 2020;8:342-52. doi: 10.1016/j.jvsv.2019.12.075.

10. Shaikh S, Patel PM, Armbrecht ES, Hurley MY. Patient survey reports association between compression stocking use adherence and stasis dermatitis flare frequency. J Am Acad Dermatol. 2020; 2:1-8. doi: 10.1016/j.jaad.2020.06.1030.

11. Tarricone A, De La Mata K, Chen S, Krishnan P, Landau S, Soave R. Relationship between $\mathrm{pH}$ shifts and rate of healing in chronic nonhealing venous stasis lower-extremity wounds. J Foot Ankle Surg. 2020;59:748-52. doi: 10.1053/j.jfas.2020.01.007.

12. Meulendijks AM, Franssen WMA, Schoonhoven L, Neumann HAM. A scoping review on chronic venous disease and the development of a venous leg ulcer: the role of obesity and mobility. J Tissue Viability. 2020;29:190-6. doi: 10.1016/j.jtv.2019.10.002.

13. Haywood C, Sumithran P. Treatment of obesity in older persons: a systematic review. Obes Rev. 2019; 20:588-98. doi: 10.1111/obr.12815.

14. Guo JD, Hlavacek P, Rosenblatt L, Keshishian A, Russ C, Mardekian J, et al. Safety andeffectiveness of apixaban compared with warfarin among clinicallyrelevant subgroups of venous thromboembolism patients in the United States Medicare population. Thromb Res. 2020;198:163-70. doi: 10.1016/j. thromres.2020.11.039.

15. Feldo M, Wojciak-Kosior M, Sowa I, Kocki J, Bogucki $\mathrm{J}$, Zubilewicz T, et al. Effect of diosmin administration in patients with chronic venous disorders on selected factors affecting angiogenesis. Molecules. 2019;24:1-11. doi: 10.3390/molecules24183316. 
16. Kakkos SK, Nicolaides AN. Efficacy of micronized purified flavonoid fraction (Daflon®) on improving individual symptoms, signs and quality of life in patients with chronic venous disease: a systematic review and meta-analysis of randomized doubleblind placebo-controlled trials. Int Angiol. 2018;37: 143-54. doi: 10.23736/S0392-9590.18.03975-5.
17. de Godoy JM. Treatment of stasis dermatitis using aminaphtone: a case series. J Med Case Rep. 2010;4:295-8. doi: 10.1186/1752-1947-4-295.

18. Nedorost S, Hammond M. Art of prevention: allergic sensitization through damaged skin. Atopic, occupational, and stasis dermatitis. Int $\mathrm{J}$ Women's Dermatol. 2020;6:381-83. doi: 10.1016/j. ijwd.2020.08.004. 